\title{
Cost/Effectiveness Treatment of Acute Renal Failure Secondary to Multiple Myeloma with Filters High Cut off
}

Rafael Alvarez Lipe*, Ana Berni Wennekers, Pilar Martín Azara, Jose Esteban Ruiz Laiglesa and Beatriz Bergasa Liberal

University Hospital Lozano Blesa of Zaragoza, Spain

*Corresponding author: Rafael Álvarez Lipe, Head of Nephrology Service, University Hospital Lozano Blesa, Nephrology, San Juan Bosco 15, 50008, Zaragoza, Spain, Tel: 609654051; E-mail: ralvarezl@senefro.org

Received date: May 3, 2016; Accepted date: May 23, 2016; Publication date: May 31, 2016

Copyright: $\odot 2016$ Lipe RA, et al. This is an open-access article distributed under the terms of the Creative Commons Attribution License; which permits unrestricted use; distribution; and reproduction in any medium; provided the original author and source are credited.

\begin{abstract}
Introduction: Treatment of Multiple Myeloma with high cut off filters was started in 2007.

Working hypothesis: The High Cut Off hemodialysis is a cost-efficient treatment.

Objective: To demonstrate that a combination treatment of chemotherapy and High cut off dialysis improves patient survival and quality of life, while saving costs by chronic dialysis.

Methodology: Up to 13 treatments with HCO filters have been applied in the University Hospital Lozano Blesa of Zaragoza to patients with acute renal failure (ARF) secondary to Multiple myeloma.

Results: 13 treatments were performed on 12 patients with high cut off hemodialysis. Six patients were diagnosed with monoclonal gammopathy Kappa and 6 were diagnosed with monoclonal gammopathy Lambda, with high levels of light chains in serum over $500 \mathrm{mg} / \mathrm{L}(11,036 \mathrm{mg} / \mathrm{L}$ on average at the beginning). We have achieved an improvement of renal function and have allowed the patient to live without dialysis dependence in $77 \%$. We demonstrated that the savings would be 11.782 Euros.
\end{abstract}

Discussion: This paper focused on the idea that although the high cost of high cut off filters is an inconvenience, this should not impede their use because the technique has been proven more effective and cost efficient

Conclusion: The treatment is cost-effective; cost savings can be estimated in more than 11,000 euros/patient.

Keywords: Multiple myeloma; Acute renal failure; Filters high cut off

\section{Introduction}

Multiple Myeloma (MM) represents $13 \%$ of hematologic cancers [1]. It is characterized by an uncontrolled proliferation of plasma cells, producing large amounts of free light chains (FLCs) which can cause obstruction of the renal tubule. Up to $40 \%$ of patients develop kidney failure and 10 to $15 \%$ require dialysis

The causes of renal dysfunction in patients with myeloma includes a proximal and distal tubular cell damage by alteration of the filtered light chains (FLCs), cast nephropaty, amyloidosis, deposition disease light chains or heavy [2], crioglobulinemia, interstitial infiltration by plasma cells, and rarely a proliferative glomerulonephritis or interstitial nephritis [3].

Life expectancy is less than 1 year with renal failure, although treatment can extend up to 5-7 years [4,5].

Treatment of acute renal failure rests on three pillars: eliminate factors that aggravate nephrotoxicity and forming cylinders, eliminate or reduce production by FLCs neoplastic cells, and eliminate or reduce FLC.
Three methods have been used to remove these free light chains in the blood: plasmapheresis, dialysis filters $\mathrm{HCO}$, and recently supra HFR.

Treatments of Multiple Myeloma with high cut-off (HCO) filters were started in 2007 , beginning with a $1.1 \mathrm{~m}^{2}$ surface HCO filter, and then increasing to a $2.1 \mathrm{~m}^{2}$ surface. In 2012 Hutchison [6] published 67 treatments of acute renal failure secondary to multiple myeloma and 2011 Grima [7] published in a study based on a cost-effective model, comparing treatment with HCO filters to conventional dialysis treatment. The cost savings explained by Grima are based on avoiding chronic hemodialysis; the model predicted a survival of 20 months in standard dialysis, as opposed to a survival of 34 months "using the HCO filters, and because treatment with HCO filters avoids the use of dialysis, the patients would also experience higher quality of life".

\section{Working Hypothesis}

The High Cut Off hemodialysis, is a cost-efficient treatment.

\section{Objective}

To demonstrate that a combination treatment of chemotherapy and High cut off dialysis improves patient survival and quality of life, while saving costs by chronic dialysis. 


\section{Methodology}

This is a descriptive study. In the period between July 2011 and February 2015 (44 months). Up to 13 treatments with HCO filters had been applied in the University Hospital Lozano Blesa of Zaragoza to patients with acute renal failure (ARF) secondary to Multiple myeloma

\section{Selection criteria}

Patients with acute renal failure secondary to multiple myeloma requiring dialysis.

\section{Levels of blood free light chain higher than $500 \mathrm{mg} / \mathrm{L}$}

Dialysis protocol: A Integra ${ }^{\oplus}$ monitor $\left(\mathrm{Hospal}^{\circ}\right)$ was used, equipped with ultrafilters of $1.4 \mathrm{~m}^{2}$, ultrapure water, bicarbonate cartridge $\left(\right.$ Bicart $\left.{ }^{\circ}\right)$ and centralized acid in a closed circuit, vascular access through a Shalldon ${ }^{\bullet}$ central catheter and heparinization with sodium heparin at $1 \%$.

The dialyzer used in each case is a HCO filter with a surface of 2.1 $\mathrm{m}^{2}$ made of polyarylethersulfone/polyvinylpyrrolidone (Theralite ${ }^{\circledR}$ ) from Gambro .

Dialysis treatments took place daily for six sessions, and later proceeded to happen every other day until levels of FLC in blood were reduced to less than $500 \mathrm{mg} / \mathrm{L}$ or the recovery of renal functions allowed them to dispense with dialysis.

The duration of dialysis was six hours INCLUDING a low blood flow between 250 and $300 \mathrm{ml} / \mathrm{min}$, bath fluid flow $500 \mathrm{ml} / \mathrm{min}$.

During dialysis sessions levels of renal function, FLCs, calcium, phosphorus, ions and albumin were monitored.

For the economic evaluation we took an approach similar to the one used by Grima used to calculate costs. Therefore, we have based our investigation essentially on the cost of the HCO filter, the albumin, dialysis lines, heparin circuit Prontoprime ${ }^{\oplus}$ priming liquid, dialysis

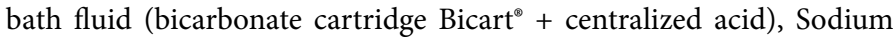
heparin, $20 \mathrm{ml}$. syringe, physiological sodium solution and Shalldon ${ }^{\circ}$ temporary catheter. Because these patients were considered as any other acute patients increased staff was not required and the two extra hours of nurse assistance included by Grima was not used.

In order to be able to compare the results we have chosen to accept the estimated survival time published by Grima. Survival of our patients should be evaluated in the long term, but so far we can claim that 3 patients have survived without dialysis for more than 3 years.

The two main limitations of the study were the lack of a control group and a small number of patients.

\section{Results}

We present our experience in the period between July of 2011 and February of 2015 (44 months). 13 treatments with high cut off hemodialysis were performed on 12 patients, 9 men and 3 women with a mean age of 60.8 years and range between 43 and 71 years. 6 patients were diagnosed with monoclonal gammopathy Kappa and 6 were diagnosed with monoclonal gammopathy Lambda, with high levels of serum free light chains over $500 \mathrm{mg} / \mathrm{L}(11.036 \mathrm{mg} / \mathrm{L}$ on average at the beginning).

A total of 151 dialysis sessions were performed, and patients stayed on a dialysis treatment with the HCO filter an average of 11.53 sessions with a range between 6 and 27 sessions. The patients, 9 male and 3 female, were on average 60.8 years old and their ages varied between 43 and 71 years old.

Regarding the bone marrow infiltration, we can say that we know the result in 10 patients and all of them had high levels of plasma cells (in a case there is evidence of plasmacytoma) that varied between $13 \%$ and $93 \%$.

In 10 out of the 13 cases (77\%) we improved the renal function of our patients enough to allow them to live without depending on a dialysis, proving the technique is effective in both the Kappa and Lambda chains, with a elimination percentage per dialysis of $58 \%$, similar to the one obtained by other authors, who found loss between the 53 and $57 \%$ [7] and a final reduction in chains over $93 \%$.

The cost of the HCO filter Theralite ${ }^{\oplus}$ from Gambro ${ }^{\circledR}$ in our hospital is 825 euros, the cost of each $50 \mathrm{ml}$ vial of Human Albumin $20 \%$ solution is 17.68 euros, the rest of the material (lines, temporary catheter, dialysis bath, priming solution (Prontoprime $\left.{ }^{\star}\right)$, Sodium heparin, physiological serum, and a $10 \mathrm{cc}$ syringe) cost 82.06 euros. Thereby, the total cost of a dialysis with HCO filter is 924.76 (Table 1).

\begin{tabular}{|l|l|}
\hline Material & Price \\
\hline Dialyzer & 825 \\
\hline Albumin & 17,68 \\
\hline Linrd & 4,73 \\
\hline Dialysis Bath & 3,93 \\
\hline Prontoprime & 3,87 \\
\hline Heparin & 3,20 \\
\hline Physiological serum & 0,66 \\
\hline Syringe & 0,026 \\
\hline Temporary Catheter & 65,67 \\
\hline TOTAL & 924,76 \\
\hline
\end{tabular}

Table 1: Cost of the hemodialysis with HCO filters. Material and medicine prices euros H.U Lozano Blesa Zaragoza Spain.

The total sessions that occurred during the 13 treatments was 151 sessions, each patient did an average of 11,53 sessions, for a total cost of 10.866 euros per treatment.

The cost per dialysis session in our hospital from the year 2011 to 2014 (the studied period) including the costs of pharmacy and supplies (dialysis equipment, lines, fluids, dialyzers, ultrafilters, catheters, etc.) was $87^{\prime} 11$ euros per session on average, this information was obtained from the nephrology services reports.

A patient usually requires of 3 weekly sessions, 156 yearly sessions, for a total estimated cost of 13589 euros.

If we consider Grima's work, average survival time of patients with Multiple Myeloma with dialysis' is 20 months, which represents a cost of 260 sessions x 87.11 euros, totaling 22.648 euros; therefore, we could save up to 11.782 euros (Table 2). 


\begin{tabular}{|l|l|l|l|}
\hline HD Type & $\mathbf{N}^{\circ}$ Sessions & Cost/Session & Total \\
\hline HCO & 11,53 & 842,45 & 10.866 \\
\hline Standard & 250 & 87,11 & 22.648 \\
\hline Saving & & & 11.782 \\
\hline
\end{tabular}

In our opinion and once we have examined the bibliography, the treatment modality in which we get the best results [16-19] is hemodialysis (HD) with dialysis membranes of very high permeability high-cut-off (HCO), these membranes have a pore size between 45 and $60 \mathrm{KDa}$, and are designed specifically for the kidney of the myeloma, but they present some disadvantages like the high loss of albumin and an elevated cost.

Table 2: Cost savings. Comparison of the cost of a dialysis session with HCO filters or conventional average number of sessions patient, cost per session, total cost y total savings per treatment. High cut off ( $\mathrm{HCO})$ filters; Hemodialysis (HD): Number sessions ( $\mathrm{N}^{\circ}$ sessions).

\section{Discussion}

The myeloma kidney treatment is oriented to reduce the exposure of the kidney to the FLCs. This is managed by acting on the Multiple Myeloma through chemotherapy treatment (dexamethasone, bortezomid, ciclophosphamide, etc) to reduce its production, at the same time they are used as adjuvant treatment techniques using extracorporeal depuration to eliminate FLCs [8-10].

The recovery of the renal function will depend not only on the reduction of the circulating FLCs, but also on the speed in which we can achieve this reduction, as Hutchison published [11].

Our results are similar to those published by Hutchinson in 2012 with sixty-seven patients with dialysis-dependent renal failure secondary to Multiple Myeloma, the median number of hemodialysis HCO sessions was 11 (range 3-45), the median number sessions in our Hospital was 11, 53 (range 4-27), 63\% of population became independent of dialysis in the study of Hutchinson, versus $77 \%$ in our initial attempt to eliminate the plasma FLCs was performed with plasmapheresis, and although the initial studies seemed promising, later it was proved that the elimination of FLCs is limited, due to the distribution of FLCs in the body ( $80 \%$ extravascular) and to the extremely big size of the plasmafilter pores, which is why a high quantity of other essential proteins are lost [12].

Recently the hemodiafiltration with endogenous reinfusion (HFR) has emerged, a technique that combines convection, diffusion and adsorption. This treatment requires a capillary dialyzer with double chamber; initially a thin membrane with high permeability is used to allow the passing of FLCs, specially kappa, a ultrafiltration takes place and this ultrafiltration passes through a cartridge of adsorptive resin in which toxins attached to proteins are stopped, and theorically the FLCs are stopped as well, with the advantage of not adsorbing the albumin once regenerated the FLCs are infused between the two chambers of the dialyzer $[13,14]$. The second chamber of the dialyzer is a low permeability membrane and in it takes place a conventional HD.

In a recent report de Pascalli published in 2015 [15] suprahemodiafiltration in combination with chemotherapy effectively reduced serum free light chains without need for albumin replacement, As in previous studies only 4 patients were treated, allowing us to draw few conclusions.

Considering the limitations of the HFR for the elimination of FLCs Lambda, and the reservations we must have because of the limited number of patients examined, we can only infer that the HFR achieves a reduction of the FLCs Kappa without having albumin loss, studies with more patients should be performed to confirm that is an effective technique for the treatment of acute renal failure secondary to multiple myeloma.

The treatment with HCO filters assures good results in the elimination of both Kappa and Lambda chains, overcoming the limitation shown by the HFR that only has good results in the elimination of Kappa chains.

In this study we have focused on proving that one of the main disadvantages discussed, high cost, shouldn't be an obstacle for its application, since it actually is the technique that has been proved to be most effective in our study and, that this technique is cost efficient we have made clear in this work, even without taking into account the indirect costs like sanitary transport, staff costs during the months the patient would stay on chronic hemodialysis, etc. Therefore, we believe that should treatment using high cut off filter be the chosen technique for a patient with acute renal failure secondary to kidney myeloma.

\section{Conclusions}

The combined treatment of chemotherapy and dialysis with HCO filters has been effective in treating acute renal failure secondary to multiple myeloma in $77 \%$ of the cases.

The treatment is cost-efficient, with savings estimated in more than 11,000 euros per patient.

\section{References}

1. Raab MS, Podar K, Breitkreutz I, Richardson PG, Anderson KC (2009) Multiple myeloma. Lancet 374: 324-339.

2. Lin J, Markowitz GS, Valeri AM, Kambham N, Sherman WH, et al. (2001) Renal monoclonal immunoglobulin deposition disease: the disease spectrum. J Am Soc Nephrol 12: 1482-1492.

3. Ivany B (1990) Frequency of light chain deposition nephropathy relative to renal amyloidosis and Bence-Jones cast nephropathy in a necropsy study of patients with myeloma. Arch Pathol Lab Med 114: 986-987.

4. Kyle RA, Gertz MA, Witzig TE, Lust JA, Lacy MQ, et al. (2003) Review of 1027 patients with newly diagnosed multiple myeloma. Mayo Clin Proc 78: 21-33.

5. Martín Reyes G, Valera A, Frutos MA, Ramos B, Ordóñez V, et al. (2003) [Survival of myeloma patients treated with dialysis]. Nefrologia 23: 131-136.

6. Hutchison CA, Heyne N, Airia P, Schindler R, Zickler D, et al. (2012) Immunoglobulin free light chain levels and recovery from myeloma kidney on treatment with chemotherapy and high cut-off haemodialysis. Nephrol Dial Transplant 0: 1-6.

7. Grima DT, Airia P, Attard C, Hutchison CA (2011) Modelled costeffectiveness of high cut-off haemodialysis compared to standard haemodialysis in the management of myeloma kidney Current Medical Research \& Opinion 27: 383-391.

8. Hutchison CA, Bradwell AR, Cook M, Basnayake K, Basu S, et al. (2009) Treatment of acute renal failure secondary to multiple myeloma with chemotherapy and extended high cut-off hemodialysis. Clin J Am Soc Nephrol 4: 745-754.

9. Isaac J, del Castillo GH (2013) New alternatives in the treatment of myeloma kidney. Nefrologia 33: 443-447.

10. Hutchison CA, Cockwell P, Reid S, Chandler K, Mead GP, et al. (2007) Efficient removal of immunoglobulin free light chains by hemodialysis for 
Citation: Lipe RA, Wennekers AB, Azara PM, Laiglesa JER, Liberal BB (2016) Cost/Effectiveness Treatment of Acute Renal Failure Secondary to Multiple Myeloma with Filters High Cut off . J Nephrol Ther 6: 249. doi:10.4172/2161-0959.1000249

Page 4 of 4

multiple myeloma: in vitro and in vivo studies. J Am Soc Nephrol 18: 886-895.

11. Hutchison CA, Cockwell P, Stringer S, Bradwell A, Cook M, et al. (2011) Early reduction of serum-free light chains associates with renal recovery in myeloma kidney. J Am Soc Nephrol 22: 1129-1136.

12. Minana JME, Parra ML, Pérez VLL, Ibanez DA (2013 New alternatives in the treatment of painful shoulder syndrome. Nefrologica 33: 443-447.

13. Testa A, Dejoie T, Lecarrer D, Wratten M, Sereni L, et al. (2010) Reduction of free immunoglobulin light chains usin adsorption properties of haemodiafiltration with endogenous reinfusion. Blood Purif 30: 34-36.

14. Pendón-Ruiz de Mier MV, Ojeda-López R, Alvarez de Lara-Sánchez MA, Martín-Malo A, Aljama-García P (2013) Effectiveness of haemodiafiltration with ultrafiltrate regeneration in renal failure due to multiple myeloma. Nefrologia 33: 426-428.

15. Pasquali S, Iannuzzella F, Corradini M, Bovino SMA (2015) A novel option for reducing free light chains in myeloma kidney: supra- hemodiafiltration with endogenous reinfusion (HFR) Journal of Nephrology 28: 251-254.

16. Martan G, Toledo R, Torres A, Sola E, Blanca L, et al. (2012) Tratamiento con hemodialisis del fracaso renal agudo en el mieloma mulltiple con filtros de alto poro (high cut off) Nefrologia 32: 35-431.

17. Khalafallah A, Wuong S, Love S, Mohamed M, Mace R, et al. (2013) Early application of High Cut-of Haemodialysis for de novo myeloma nephropathy is associated with long-term dialysis independency and renal recovery. Mediterr J Hematol Infect Dis 5: e2013007.

18. Basnayake K, Hutchison C, Kamel D, Sheaff M, Ashman N, et al. (2008) Resolution of cast nephropathy following free light chain removal by haemodialysis in a patient with multiple myeloma: a case report. J Med Case Rep 2: 380.

19. Hutchison CA, Harding S, Mead G, Goehl H, Storr M, et al. (2008) Serum free-light chain removal by high cutoff hemodialysis: optimizing removal and supportive care. Artif Organs 32: 910-917. 